\title{
PENGELOLAAN UNTUK PENDIDIKAN INKLUSIF EFEKTIF
}

\author{
Alya Shofa Faradila \\ Program Studi Pendidikan Bahasa Inggris, Fakultas Keguruan dan Ilmu Pendidikan \\ Universitas Lambung Mangkurat, Banjarmasin \\ Email: alyashofafaradila@gmail.com
}

\begin{abstract}
Abstrak
Pengelolaan adalah proses, cara, suatu perbuatan mengelola, atau proses menjalankan kegiatan tertentu dengan menggerakan tenaga orang lain. Pengelolaan adalah proses yang memberikan pengawasan pada semua hal yang terlibat dalam pelaksanaan kebijaksanaan dan pencapaian tujuan. Pengelolaan atau manajemen ialah proses tertentu yang akan dilaksanakan mulai perencanaan sampai dengan penilaian. Tujuan dari pengelolaan pendidikan adalah tercapainya tujuan pendidikan secara efektif dan efisien. Penelitian ini menggunakan penelitian kualitatif untuk mendeskripsikan proses kegiatan pendidikan berdasarkan yang terjadi di lapangan. Hasil dari penelitian menemukan bahwa kepala sekolah merupakan peran penting dalam pengelolaan pendidikan inklusif. Peneliti juga akan melakukan perbandingan beberapa pengelolaan atau manajemen.
\end{abstract}

Kata Kunci: pengelolaan, manajemen, pendidikan inklusif, kepala sekolah

\begin{abstract}
Management is a process, method, an act of managing, or the process of carrying out certain activities by mobilizing other people's energy. Management is a process that provides oversight on all matters involved in implementing policies and achieving goals. Management or management is a certain process that will be carried out from planning to assessment. The purpose of education management is the achievement of educational goals effectively and efficiently. This study uses qualitative research to describe the process of educational activities based on what happens in the field. The results of the study found that the principal is an important role in the management of inclusive education. Researchers will also conduct a comparison of some control or management.
\end{abstract}

Keywords: management, management, inclusive education, principal

\section{PENDAHULUAN}

Pengelolaan pendidikan adalah suatu rangkaian kegiatan dalam merencanakan, mengendalikan, mengorganisasikan dan mengembangkan segala upaya dalam mengatur sarana 
dan prasarana untuk mencapai suatu tujuan pendidikan. Berdasarkan pengertiannya pengelolaan berasal dari kata manajemen, istilah manajemen dari kata administrasi. Administrasi pendidikan sebagai ilmu pengetahuan yang membahas pendidikan dalam sudut pandang proses kerjasama antar manusia terhadap meningkatkan potensi peserta didik dalam perubahan sikap sebagai pembelajaran untuk mencapai tujuan pendidikan efektif dan efisien. Pengelolaan pendidikan penting untuk dibutuhkan kepada pendidik yang berfungsi dalam mengatur atau melayani yang dimaksud mengatur atau melayani dalam pengelolaan pendidikan yaitu proses untuk meyakinkan bahwa aktivitas sebenarnya sesuai dengan yang direncanakan.Penerapan ilmu manajemen dalam dunia pendidikan atau sebagai penerapan manajemen dalam pembiaan, pengembangan dan pengendalian usaha dan praktek pendidikan (Sagala, 2004:27). Manajemen pendidikan ialah aplikasi prinsip, konsep dan teori manajemen dalam aktivitas pendidikan untuk mencapai tujuan pendidikan secara efektif dan efisien.

Berdasar pada pengertian manajemen pendidikan adanya ciri-ciri atau pengertian manajemen pendidikan yang ada dalam ketentuan tersebut sebagai berikut; [1] manajemen adalah kegiatan atau rangkaian kegiatan yang dilakukan dari, oleh dan bagi manusia. [2] rangkaian kegiatan itu merupakan suatu proses pengelolaan dari suatau rangkaian kegiatan pendidikan yang sifatnya komplek dan unik yang berbeda dengan tujaun perusahaan untuk memperoleh keuntungan yang sebesar-besarnya, tujuan ini tidak terlepas dari tujuan pendidikan secara umum dan tujuan pendidikan yang telah diterapkan oleh suatu bangsa kegiatan pendidikan. [3] manajemen proses itu dikerjakan bersama oleh sekelompok manusia yang terbentuk dalam suatu organizasi sehingga kegiatannya harus dijaga supaya tercipta kondisi kerja yang selaras tanpa menghentikan unsur-unsur manusia yang nampak dalam kegiatan pendidikan itu. [4] Proses itu dilakukan dalam rangka meraih suatu tujuan yang telah diangkat sebelumnya, yang dalam hal ini melibatkan tujuan yang bersifat umum "skala tujuan umum" dan yang diembang oleh tiap-tiap organizasi pendidikan "skala tujuan khusus" Proses pengelolaan itu dibuat agar tujuannya dapat dicapai secara efektif dan efisien. (Mulyani A. Nurhadi, 1983:PP 2-3). "Suatu usaha bersama yang dilakukan untuk mendayagunakan semua sumber daya baik manusia, uang, bahan dan peralatan serta metode untuk mencapai tujuan pendidikan secara efektif dan efisien" (Purwanto \& Djojopranoto, 1981:14) (Purwanto \& Djojopranoto, 1981:14). 
Pendidikan inklusif berarti sistem layanan pendidikan yang mensyaratkan anak disabilitas belajar di sekolah-sekolah terdekat di kelas biasa bersama teman-teman seusianya, selain memuat anak-anak yang memiliki kelainan juga menampung anak-anak yang memiliki bakat atau kecerdasan luar biasa untuk dapat belajar bersama-sama dalam satu kelas. Pengertian pendidikan inklusi adalah sekolah harus mengakomodasi semua anak tanpa memandang kondisi fisik, intellectual, sosial emosional, linguistik atau kondisi lainnya, Menurut Hildegun Olsen (Tarmansyah, 2007;82). Ini harus mencakup anak-anak penyandang cacat, berbakat. Anak yang berasal dari populasi etnis minoritas, linguistik, atau budaya dan anak-anak dari area atau kelompok yang kurang beruntung atau termajinalisasi. "Sekolah yang menampung semua murid di kelas yang sama" (Stainback,1980). Pendidikan yang layak, menantang, tetapi disesuaikan dengan kemampuan dan kebutuhan setiap murid maupun bantuan dan dukungan yang dapat diberikan oleh para guru, agar anak-anak berhasil, adalah penyedia program dari sekolah. Berdasarkan Peraturan Menteri Nasional Pendidikan (Permendiknas) Nomor 70 Tahun 2009 pasal 1 dikatakan bahwa yang dimaksud dengan pendidikan inklusif adalah sistem pimpinan pendidikan yang memberikan kesempatan kepada semua siswa yang memiliki perbedaan dan potensi kecerdasan atau bakat istimewa untuk mengikuti pendidikan atau pembelajaran dalam lingkungan pendidikan secara bersama-sama.

Menurut Joseph S. Agbenyega \& Umesh Sharma (2014:116) menerapkan pendidikan inklusif di sekolah memerlukan perubahan yang signifikan dalam cara pemimpin sekolah bertindak dan menanggapi tantangan sehari-hari yang dihadapi sekolah dalam memenuhi kebutuhan siswa dengan kemampuan yang beragam. Untuk memahami peran penting yang dimainkan oleh para pemimpin sekolah dalam memimpin sekolah inklusif, penting untuk terlebih dahulu mendefinisikan pendidikan inklusif. Pendidikan inklusif pertama dan terpenting adalah pendidikan berkualitas tinggi semua daripada pendidikan khusus. Guru dan staf sekolah memiliki peran penting bagi keberhasilan implementasi dan keberlanjutan pendidikan inklusif (Amka, 2019:87). Sekolah inklusi merupakan sekolah regular ataupun sekolah umum yang menerima anak ABK untuk belajar berdampingan dengan siswa normal dalam satu naungan kegiatan pembelajaran. (Rahmah Nurfitriani \& Muhammad Almi Hidayat, 2020:78) Jurnal Pendidikan Guru Madrasah Ibtidaiyah. 


\section{METODE}

Reset ini menggunakan metode penelitian kualitatif dimana untuk menggambarkan proses kegiatan pendidikan berdasarkan yang terjadi di lapangan sebagai bahan pembahasan lanjut dan menemukan kekurangan serta kelemahan pendidik agar dapat ditentukan sarana penyempurnaannya. Metode penelitian ini juga untuk menafsirkan dan menganalisis adanya fakta dan peristiwa pendidikan yang terjadi di lapangan pada konteks ruang dan waktu dan dalam situasi lingkungan pendidikan. Penelitian kualitatif adalah process penelitian yang berlandaskan pada filsafat post positivisme, digunakan untuk meneliti pada kondisi obyek yang alamiah, (sebagai lawannya eksperimen) dimana peneliti adalah sebagai instrumen kunci, pengambilan sample sumber data dilakukan secara purposive dan snowball, teknik pengumpulan dengan tri-anggulasi (gabungan), bersifat inductive atau kualitatif (Sugiyono, 2011). Menurut Saryono (2010), menemukan, menggambarkan, dan menjelaskan kualitas atau keistimewaan dari pengaruh social yang tidak dapat dijelaskan, diukur atau digambarkan melalui pendekatan kuantitatif, penelitian kualitatif merupakan penelitian yang digunakan untuk menyelidiki. Dalam penelitian kualitatif pengujian dalam penggunaan metode statistic tidak dilakukan.

\section{HASIL DAN PEMBAHASAN}

Dalam pengelolaan pendidikan inklusif kepala sekolah berperan penting dalam kepemimpinan. Perencanaan, pelaksaan, pengawasan serta tanggung jawab merupakan suatu pengelolaan pendidikan inklusif dan meliputi proses, administrasi dan manajemen suatu satuan pendidikan. Pengaruh yang baik kepada sekolah merupakan manajemen sekolah yang dapat mencapai tujuan pendidikan secara efektif dan efesien. Kepemimpinan penting untuk memberikan arahan, dengan fokus pada nilai dan wacana yang mendukung praktik inklusif. Menurut Lumby \& Coleman (2016), Kepemimpinan telah diartikan dengan cara yang berbeda, tetapi dapat didefinisikan sebagai proses memberikan arahan dan menerapkan pengaruh. Kepemimpinan sekolah digunakan untuk merujuk semua orang yang memegang peran kepemimpinan di sekolah dan komunitas belajar. Sebagaimana pemimpin itu disebut sebagai kepala sekolah, direktur sekolah atau kepala sekolah, serta kepemimpinan yang terjadi dalam 
tim. Peran mereka fokus membimbing bakat dan energi guru, murid, dan orang tua untuk mencapai tujuan pendidikan bersama.

Kepala sekolah berada dalam posisi kunci untuk secara sistematis merencanakan efektivitas pengajaran dengan memperhatikan berbagai variabel, seperti melindungi waktu pembelajaran, meminimalkan gangguan, mempromosikan praktik pengajaran yang kuat, mendorong pembelajaran guru, memantau kemajuan siswa, dan memberikan umpan balik khusus kepada guru tentang mereka (Deshler \& Cornett, 2012). Menurut Billingsley dkk (2014), selain bidang kepemimpinan ini, kepala sekolah mendukung sekolah inklusif yang efektif melalui kepemimpinan instruksional, yang mencakup ekspektasi pencapaian tinggi, iklim disipliner yang positif, pengajaran yang efektif dan pemantauan kemajuan, kondisi kerja yang mendorong efektivitas pengajaran, dan dukungan untuk pembelajaran profesional berkelanjutan. Menurut Joseph S. Agbenyega Umesh Sharma (2014:116), menerapkan pendidikan inklusif di sekolah memerlukan perubahan yang signifikan dalam cara pemimpin sekolah bertindak dan menanggapi tantangan sehari-hari yang dihadapi sekolah dalam memenuhi kebutuhan siswa dengan kemampuan yang beragam. Sekolah inklusif perlu dipantau oleh pemimpin agar kemajuan sekolahnya teratur. Menurut Khalifah dkk (2016), pemimpin harus mampu mempromosikan dan mempertahankan lingkungan yang stabil untuk merekrut dan mempertahankan guru terbaik untuk anak-anak dan remaja yang terpinggirkan. Lebih dari apa pun, komitmen terhadap sekumpulan nilai inti oleh guru dan pengelola adalah bagian dari apa yang membuat sekolah inclusive berhasil (McLeskey \& Waldron, 2015:69). Setiap orang di sekolah inklusif menjalankan program pengembangan profesional tentang undang-undang dan kebijakan yang relevan yang terkait dengan siswa penyandang disabilitas dan pendidikan mereka yang dipastikan oleh pemimpin inklusif.

\section{KESIMPULAN}

Pendidikan inklusi di Indonesia ialah cara pemerintah agar selalu memberikan layanan pendidikan ke masyarakat dengan terbuka dan tidak diskriminatif untuk anak normal ataupun anak yang berkebutuhan khusus. Penyokong utama untuk tetap memastikan siswa berkebutuhan khusus agar selalu menerima pendidikan yang berkualitas tinggi adalah kepala sekolah. Pengembangan dan mendukung sekolah yang inklusif dan efektif merupakah keterlibatan oleh kepala sekolah untuk meningkatkan pencapaian tinggi untuk semua siswa, dan memastikan pengajaran pendidikan yang efektif serta memastikan peluang pembelajaran 
profesional untuk meningkatkan praktik guru. Kepala sekolah dapat menciptakan dan mendukung sekolah inklusif dengan menetapkan dan menyampaikan visi, memfasilitasi pengalaman belajar berkualitas tinggi bagi siswa, membangun kapasitas profesional, menciptakan organisasi yang mendukung untuk belajar dan terhubung dengan mitra eksternal (Hitt \& Tucker, 2016).

Kesimpulan yang dapat diambil ialah perlunya peningkatan persiapan kepala sekolah dengan kebutuhan siswa berkebutuhan khusus dan yang berjuang baik akademis dan perilaku di sekolah. Persiapan kepala sekolah yang baik untuk mendukung pengajaran efektif dan dapat berdampak pada kesenjangan untuk siswa disabilitas.Dalam Jurnal Pendidikan dan Kebudayaan oleh Amka (2019) saat ini sebagian besar sekolah penyelenggara inklusif, diketahui masih terkendala ketersediaan guru dengan latar belakang sarjana Pendidikan Luar Biasa (PLB) atau sarjana Pendidikan Khusus (PKh). Menurut Amka (2019:99) dalam Jurnal Pendidikan dan Kebudayaan manajemen pendidikan inklusif di kelas oleh guru dilaksanakan dengan kerja sama antara para guru, antara guru umum dan guru pendidikan khusus, antara guru berpengalaman dengan guru yang belum berpengalaman.

\section{REFERENSI}

Sugiyono. (2008). Metode penelitian pendidikan:(pendekatan kuantitatif, kualitatif dan R \& D). Alfabeta.

Amka, A. (2019). PENDIDIKAN INKLUSIF BAGI SISWA BERKEBUTUHAN KHUSUS DI KALIMANTAN SELATAN. PENDIDIKAN INKLUSIF BAGI SISWA BERKEBUTUHAN KHUSUS DI KALIMANTAN SELATAN, 4(01).

Kusumastuti, D. E. (2019). Kontribusi Pemerintah Daerah Provinsi Kalimantan Selatan Dalam Implementasi Pendidikan Inklusi. Jurnal Sagacious, 5(2), 91-96.

Hariza, B. N., Tiana, H., Rahmah, N., \& Yulianti, P. S. MANAJEMEN KELEMBAGAAN PENDIDIKAN INKLUSI DI SDN TELUK DALAM 1 BANJARMASIN.

Ratnasari, V. (2020). MANAJEMEN PENGELOLAAN GURU PENDAMPING KHUSUS DI SEKOLAH INKLUSI SEKOLAH DASAR NEGERI SEMANGAT DALAM 2.

Sumarni, M. S. (2019). Pengelolaan Pendidikan Inklusif di Madrasah. Edukasi, 17(2), 294355. 
Agustin, I. (2019). Permasalahan dalam Penyelenggaraan Pendidikan Inklusi di SDN Se Kecamatan Soko Kabupaten Tuban. ELSE (Elementary School Education Journal): Jurnal Pendidikan dan Pembelajaran Sekolah Dasar, 3(2), 17-26.

Nurfitriani, R., \& Hidayat, M. A. (2020). Strategi Pengelolaan Siswa ABK Jenis Tunagrahita di Kelas Inklusi. At-Thullab: Jurnal Pendidikan Guru Madrasah Ibtidaiyah, 4(2), 78-92.

Óskarsdóttir, E., Donnelly, V., Turner-Cmuchal, M. and Florian, L. (2020), "Inclusive school leaders - their role in raising the achievement of all learners", Journal of Educational Administration, Vol. 58 No. 5, pp. 521-537.

Agbenyega, J.S. and Sharma, U. (2014), "Leading Inclusive Education: Measuring 'Effective' Leadership for Inclusive Education through a Bourdieuian Lens", Measuring Inclusive Education (International Perspectives on Inclusive Education, Vol. 3), Emerald Group Publishing Limited, pp. 115-132.

McLeskey, J., Billingsley, B. and Waldron, N.L. (2016), "Principal Leadership for Effective Inclusive Schools", General and Special Education Inclusion in an Age of Change: Roles of Professionals Involved (Advances in Special Education, Vol. 32), Emerald Group Publishing Limited, pp. 55-74.

DeMatthews, D., Billingsley, B., McLeskey, J. and Sharma, U. (2020), "Principal leadership for students with disabilities in effective inclusive schools", Journal of Educational Administration, Vol. 58 No. 5, pp. 539-554.

Xiaotao, Z., Yang, X., Diaz, I. and Yu, M. (2018), "Is too much inclusive leadership a good thing? An examination of curvilinear relationship between inclusive leadership and employees' task performance", International Journal of Manpower, Vol. 39 No. 7, pp. 882895. 